\title{
Gambaran Pengetahuan Klinisi Ruang Rawat Intensif mengenai Ventilator Associated Pneumonia (VAP) Bundle di Ruang Rawat Intensif RSUP Dr. Hasan Sadikin Bandung
}

\author{
M. Fajar Sadli, ${ }^{1}$ Doddy Tavianto, ${ }^{2}$ Ike Sri Redjeki ${ }^{2}$ \\ ${ }^{1}$ Rumah Sakit Umum Daerah Dr. Aziz Singkawang, ${ }^{2}$ Departemen Anestesiologi dan Terapi Intensif \\ Fakultas Kedokteran Universitas Padjadjaran/RSUP Dr. Hasan Sadikin Bandung
}

\begin{abstract}
Abstrak
Ventilator associated pneumonia (VAP) merupakan infeksi yang terjadi pada pasien yang terintubasi $\geq 48$ jam di ruang rawat intensif. Penanganan VAP merupakan tantangan utama akibat morbiditas dan mortalitas yang tinggi.Ventilator associated pneumonia bundle (VAPb) telah terbukti dapat menurunkan angka kejadian VAP sehingga pengetahuan dokter dan perawat mengenai VAPb menentukan keberhasilan pencegahan VAP di ruang rawat intensif. Tujuan penelitian ini mengetahui pengetahuan dokter dan perawat mengenai VAPb di ruang rawat intensif RSUP Dr. Hasan Sadikin Bandung. Data diambil dari bulan November-Desember 2016. Penelitian deskriptif dengan desain potong lintang ini menggambarkan pengetahuan mengenai VAPb dari dokter residen Departemen Anestesi dan Terapi Intensif dan perawat di ruang rawat intensif RSUP Dr. Hasan Sadikin Bandung. Responden terdiri atas 79 dokter dan 88 perawat. Tingkat pengetahuan VAPb diuji menggunakan 20 pertanyaan kuesioner. Responden perawat terbanyak berjenis kelamin perempuan (74\%), berusia $\geq 30$ tahun (92\%), status pendidikan diploma III (65\%), lama kerja $>5$ tahun (76\%), dan bekerja di Intensive Care Unit (ICU) (32\%). Responden dokter terbanyak berjenis kelamin laki-laki (71\%), berusia $\geq 30$ tahun (83\%), dan telah menyelesaikan stase ICU (61\%). Simpulan, nilai kuesioner perawat dan dokter rata-rata berturut-turut 73,63 dan 73,16.
\end{abstract}

Kata kunci: Klinisi ruang rawat intensif, tingkat pengetahuan, ventilator associated pneumonoia bundle

\section{Intensive Care Clinician's Knowledge onVentilator Associated Pneumonia (VAP) Bundle in the Intensive Care Unit of Dr. Hasan Sadikin Hospital Bandung}

\begin{abstract}
Ventilator associated pneumonia (VAP) is an infection that occurs in patients who are intubated for $\geq 48$ hours in intensive care. VAP Management is a major challenge due to its high morbidity and mortality. Ventilator associated pneumonia bundle (VAPb) has been shown to reduce the incidence of VAP; hence, knowledge of doctors and nurses on VAPb determines the success of preventing VAP in intensive care. This study aimed to describe the intensive care clinician's knowledge on ventilator associated pneumonia bundle in the intensive care of Dr. Hasan Sadikin General Hospital Bandung. Data were collected from November-December 2016. This cross-sectional descriptive study depicts the knowledge on VAPb among resident physicians at the Department of Anesthesia and Intensive Therapy and nurses at the Intensive Care Department of Dr. Hasan Sadikin General Hospital. Respondents consisted of 79 doctors and 88 nurses. The level of knowledge on VAPb was tested using a 20-question questionnaire. Most nurse respondents were female (74\%), aged $\geq 30$ years $(92.0 \%)$, diploma III graduates (65\%), length of employment of $>5$ years (76\%), and Intensive Care Unit staff (ICU) (32\%). Most physician respondents were male (71\%), aged $\geq 30$ years (83\%), and had completed their rotation in ICU (61\%). In conclusion, the mean values of the result of the questionnaire for nurses and doctors are, respectively, 73.63 and 73.16 .
\end{abstract}

Keywords: Intensive care clinician, level of knowledge, ventilator associated pneumonia bundle

Korespondensi: M. Fajar Sadli, dr., SpAn, Rumah Sakit Umum Daerah Dr. Aziz Singkawang, Jalan Dr. Soetomo No. 28, Singkawang, Tlpn. 0562-631798, Email sadlifajar@ymail.com 


\section{Pendahuluan}

Ventilator associated pneumonia (VAP) adalah infeksi nosokomial paling umum yang diderita oleh pasien di ruang rawat intensif. Angka kejadian VAP mencapai 9-27\% dari seluruh pasien terintubasi dan International Nosocomial Infection Control Consortium (INICC) melaporkan insidensi VAP mencapai 13,6 per-1.000 ventilator per hari. ${ }^{1,2}$

Mortalitas pasien VAP berada pada rentang $24 \%$ sampai $50 \%$ dan akan meningkat sampai dengan $76 \%$ apabila infeksi disebabkan oleh mikroorganisme multiresisten. Risiko mortalitas pasien VAP dua kali lebih tinggi dibanding dengan pasien tanpa VAP. ${ }^{4}$ Ventilator associated pneumonia berhubungan dengan lama perawatan dan biaya perawatan pasien,oleh karena itu dibutuhkan metode untuk mencegah VAP terutama akibat mikroorganisme multiresisten. ${ }^{1,3}$

Ventilatorassociated pneumonia merupakan tantangan utama di ICU terkait morbiditas dan mortalitas yang tinggi. Institute for Healthcare Improvement (IHI) mengeluarkan sebuah rangkaian pencegahan VAP yang dinamakan $\mathrm{VAP}$ bundle (VAPb). Lima rangkaian $\mathrm{VAPb}$, yaitu elevasi (head of the bed) HOB 30-45 derajat, terapi profilaksis tromboembolik, terapi profilaksis ulkus peptikum, evaluasi sedatif harian, kesiapan esktubasi, dan perawatan oral. Penelitian di Inggris memaparkan bahwa di rumah sakit yang menggunakan prosedur $\mathrm{VAPb}$ memiliki potensi penurunan angka kejadian VAP sebesar 58\%. ${ }^{3-6}$

Keberhasilan VAPb di ruang rawat intensif oleh perawat bergantung pada standar prosedur operasional, tingkat pengetahuan perawat terhadap $\mathrm{VAPb}$, serta kepatuhan tindakan keperawatan. Beberapa studi melaporkan bahwa terdapat ketidaktahuan yang substansial pada perawat ICU terkait strategi VAPb. Penelitian di Yaman tahun 2014 yang bertujuan mengevaluasi pengetahuan perawat di ICU sebagai strategi pencegahan terhadap VAP menggambarkan bahwa nilai rata-rata kuesioner yang didapatkan hanya 47,3\% mengenai standar umum pencegahan VAP. Penelitian di Lebanon tahun 2015 menggambarkan bahwa kurang dari 50\% perawat ICU mengetahui definisi dan diagnosis VAP serta komplikasi ventilator mekanik terkait VAP. $3,7,8$

Dokter dan perawat dapat berkolaborasi dalam pencegahan VAP di ICU melalui VAPb. Peran dokter dalam VAPb terkait dengan evaluasi sedasi, pemberian terapi profilaksis ulkus peptikum dan DVT, serta indikasi intubasi. Sampai saat ini penelitian yang memberikan gambaran pengetahuan dokter mengenai $\mathrm{VAPb}$ masih sangat jarang., ${ }^{9,10}$

Rumah Sakit Umum Pusat Dr. Hasan Sadikin (RSHS) Bandung merupakan rumah sakit umum rujukan nasional yang memiliki ruang rawat intensif yang tentunya melibatkan perawat dan dokter dalam penatalaksanaan pasien. Penelitian ini bertujuan mengetahui pengetahuan dokter dan perawat mengenai $\mathrm{VAPb}$ di ruang rawat intensif RSUP Dr. Hasan Sadikin Bandung.

\section{Subjek dan Metode}

Penelitian ini merupakan penelitian deskriptif dengan pendekatan potong lintang mengenai pengetahuan VAPb di Ruang Rawat Intensif RSHS Bandung. Subjek penelitian adalah perawat ruang rawat intensif (Intensive Care Unit/ICU, Pediatric Intensive Care Unit/PICU, Neonatal Intensive Care Unit/NICU), Cardiac Intensive Care Unit/CICU, dan Neurocritical Care Unit/NCCU) serta dokter residen Departemen Anestesiologi dan Terapi Intensif Fakultas Kedokteran Universitas Padjadjaran. Penelitian dilakukan pada bulan NovemberDesember 2016.

Kriteria inklusi responden penelitian ini adalah dokter residen anestesiologi dan terapi intensif yang sedang melaksanakan stase ICU dan yang telah melewati stase ICU dan perawat ruang rawat intensif yang memiliki sertifikat pelatihan dasar ruang rawat intensif. Responden akan dieksklusikan apabila perawat berstatus sedang menjalani pendidikan dan latihan di ruang rawat intensif, serta dokter atau perawat yang sedang tidak menjalani masa tugas.

Pengambilan responden dilakukan dengan 
total sampling. Jumlah responden yang memenuhi kriteria inklusi dan tidak termasuk eksklusi terdiri atas 88 perawat dan 79 dokter. Karakteristik umum perawat yang didata berupa identitas perawat, usia, jenis kelamin, status pendidikan, lama kerja di ruang rawat intensif, dan jenis ruang rawat. Karakteristik umum dokter yang didata berupa identitas dokter, usia, jenis kelamin, dan stase ICU. Gambaran pengetahuan dokter dan perawat mengenai $\mathrm{VAPb}$ didapatkan menggunakan alat bantu kuesioner yang terdiri atas 20 pertanyaan pilihan ganda.

Karakteristik umum dokter dan perawat dideskripsikan dalam bentuk tabel distribusi frekuensi yang menampilkan jumlah (n) dan persentase (\%). Gambaran pengetahuan dideskripsikan dalam bentuk tabel dan diagram yang menampilkan rata-rata dan standar deviasi (SD). Analisis statistik dilakukan dengan bantuan aplikasi statistical product and service solution (SPSS).

\section{Hasil}

Penelitian dilakukan kepada perawat dan dokter. Jumlah responden terdiri atas 88 perawat dan 79 dokter. Karakteristik responden perawat didominasi oleh jenis kelamin perempuan, usia $\geq 30$ tahun, status pendidikan Diploma III, serta pengalaman kerja di ruang rawat intensif lebih dari 5 tahun dan bekerja di ruang rawat ICU (Tabel 1).

Jumlah responden penelitian kelompok dokter menunjukkan bahwa laki-laki lebih banyak dibanding dengan perempuan.

Tabel 1 Karakteristik Umum Responden Perawat

\begin{tabular}{lcc}
\hline \multicolumn{1}{c}{ Karakteristik } & Jumlah Responden (n) & Persentase (\%) \\
\hline Jenis kelamin & 23 & 26 \\
Laki-laki & 65 & 74 \\
Perempuan & & \\
Usia (tahun) & 7 & 8 \\
$25-29$ & 81 & 92 \\
$\geq 30$ & & \\
Status pendidikan & 57 & 65 \\
Diploma III & 29 & 33 \\
Strata I & 2 & 2 \\
Strata II & & \\
Lama kerja di ruang rawat intensif & 3 & 4 \\
$<6$ bulan & 9 & 10 \\
6 bulan-1 tahun & 9 & 10 \\
1-5 tahun & 67 & 76 \\
$>5$ tahun & & \\
Jenis ruang rawat & 28 & 32 \\
ICU & 12 & 14 \\
NCCU & 15 & 17 \\
CICU & 16 & 18 \\
PICU & 17 & 19 \\
NICU & 88 & 100 \\
\hline Total & &
\end{tabular}


Tabel 2 Karakteristik Umum Responden Dokter

\begin{tabular}{lcc}
\hline \multicolumn{1}{c}{ Karakteristik } & $\begin{array}{c}\text { Jumlah } \\
\text { Responden } \\
\text { (n) }\end{array}$ & $\begin{array}{c}\text { Persentase } \\
\text { (\%) }\end{array}$ \\
\hline Jenis kelamin & & \\
$\quad$ Laki-laki & 56 & 71 \\
Perempuan & 23 & 29 \\
Usia (tahun) & & \\
$25-29$ & 13 & 17 \\
$\geq 30$ & 66 & 83 \\
Stase ICU & & \\
ICU 1 & 15 & 19 \\
ICU 2 & 12 & 15 \\
ICU 3 & 4 & 5 \\
Pascastase ICU & 48 & 61 \\
\hline Total & 79 & 100 \\
\hline
\end{tabular}

Responden berusia 30 tahun atau lebih lebih banyak dibanding dengan responden yang berusia 25-29 tahun. Responden penelitian pascastase ICU memiliki persentase tertinggi dibanding dengan responden stase ICU yang lain (Tabel 2).

Hasil penitilian menunjukkan nilai rata-rata seluruh perawat sebesar 73,64 dengan status pendidikan Strata II memiliki nilai rerata paling tinggi dibanding dengan perawat status pendidikan Diploma III dan Strata I. Nilai ratarata perawat dengan lama kerja lebih dari 5 tahun lebih tinggi dibanding dengan nilai ratarata perawat lama kerja kurang dari 5 tahun. Perawat yang bekerja di NICU memiliki nilai rata-rata lebih tinggi daripada perawat yang bekerja di ruang rawat intensif lainnya (Tabel 3).

Nilai rata-rata responden dokter sebesar 73,16 . Survei pada dokter yang stase di ICU didapatkan bahwa dokter stase ICU 2 dan pascastase ICU memiliki nilai rata-rata yang sama sebesar 73,75 atau lebih tinggi dibanding dengan dokter stase ICU 1 dan 3 (Tabel 4).

Pengetahuan responden kelompok perawat dan dokter mengenai VAPb berdasar atas pertanyaan masing-masing pada kuesioner (Tabel 5).
Tabel 3 Tingkat Pengetahuan Perawat berdasar atas Karakteristik Umum

\begin{tabular}{lc}
\hline \multicolumn{1}{c}{ Karakteristik } & $\begin{array}{c}\text { Nilai } \\
\text { (Rata-rata } \pm \text { SD) }\end{array}$ \\
\hline Kuesioner perawat & $73,64 \pm 11,13$ \\
Status pendidikan & \\
Diploma III & $73,59 \pm 11,45$ \\
Strata I & $73,27 \pm 10,88$ \\
Strata II & $80,00 \pm 7,07$ \\
Lama kerja di ruang rawat & \\
intensif & \\
$<6$ bulan & $58,33 \pm 2,89$ \\
6 bulan-1 tahun & $73,89 \pm 12,44$ \\
1-5 tahun & $73,89 \pm 6,97$ \\
$>5$ tahun & $74,25 \pm 11,29$ \\
Jenis ruang rawat & \\
ICU & $71,79 \pm 10,99$ \\
NCCU & $75,83 \pm 8,75$ \\
CICU & $70,67 \pm 8,20$ \\
PICU & $69,37 \pm 10,14$ \\
NICU & $81,76 \pm 12,49$ \\
\hline
\end{tabular}

Keterangan: ICU=Intensive Care Unit; $\mathrm{PICU}=$ Pediatric Intensive Care Unit; $\mathrm{NICU}=$ Neonatal Intensive Care Unit; $\mathrm{CICU}=$ Cardiac Intensive Care Unit; NCCU=Neurocritical Care Unit

\section{Pembahasan}

Ventilator Associated Pneumonia bundle merupakan rangkaian pencegahan VAP yang telah dinilai efektif menurunkan angka kejadian VAP di ruang rawat intensif. Rangakaian VAPb yang terdiri atas lima pencegahan, yaitu elevasi

Tabel 4 Tingkat Pengetahuan Dokter berdasar atas Karakteristik Umum

\begin{tabular}{lc}
\hline \multicolumn{1}{c}{ Karakteristik } & $\begin{array}{c}\text { Nilai } \\
\text { (Rata-rata } \pm \text { SD) }\end{array}$ \\
\hline Kuesioner dokter & $73,16 \pm 11,18$ \\
Stase ICU & \\
ICU 1 & $72,33 \pm 14,98$ \\
ICU 2 & $73,75 \pm 10,25$ \\
ICU 3 & $67,50 \pm 15,55$ \\
Pascastase ICU & $73,75 \pm 9,87$ \\
\hline
\end{tabular}

Keterangan: ICU=Intensive Care Unit 
Tabel 5 Pengetahuan Individu berdasar atas Pertanyaan Kuesioner

\begin{tabular}{|c|c|c|c|c|}
\hline \multirow{2}{*}{ Jenis Pertanyaan } & \multicolumn{2}{|c|}{ Perawat } & \multicolumn{2}{|c|}{ Dokter } \\
\hline & $\mathbf{n}$ & $\%$ & $\mathbf{n}$ & $\%$ \\
\hline \multicolumn{5}{|l|}{ VAP muncul pada? } \\
\hline$\geq 48$ jam setelah pasien terpapar ventilator mekanik. & 75 & 85 & 71 & 90 \\
\hline \multicolumn{5}{|c|}{ Dalam merawat pasien dengan ventilator harus mencuci tangan pada saat? } \\
\hline Sebelum dan setelah suctioning oral/pipa endotrakeal. & 88 & 100 & 79 & 100 \\
\hline \multicolumn{5}{|c|}{$\begin{array}{l}\text { Pada saat kapan sarung tangan steril digunakan untuk merawat pasien dengan } \\
\text { ventilator? }\end{array}$} \\
\hline Suctioning pipa endotrakeal. & 84 & 84 & 53 & 67 \\
\hline \multicolumn{5}{|l|}{ Insersi kateter suction ke dalam pipa endotrakeal? } \\
\hline Merupakan prosedur steril. & 88 & 100 & 64 & 81 \\
\hline \multicolumn{5}{|c|}{$\begin{array}{l}\text { Sistem suction terbuka versus sistem suction tertutup, mana yang } \\
\text { direkomendasikan? }\end{array}$} \\
\hline Sistem suction tertutup direkomendasikan. & 57 & 65 & 70 & 89 \\
\hline \multicolumn{5}{|l|}{ Kapan suctioning harus dilakukan pada pasien? } \\
\hline Jika diperlukan. & 72 & 82 & 51 & 65 \\
\hline \multicolumn{5}{|l|}{ Kapan perawat diharuskan untuk mengganti kateter suction? } \\
\hline Segera setelah pertama kali digunakan. & 80 & 91 & 58 & 73 \\
\hline \multicolumn{5}{|c|}{ Elevasi kepala terhadap tempat tidur harus dilakukan antara berapa derajat? } \\
\hline $30-45$ derajat. & 55 & 62 & 68 & 86 \\
\hline \multicolumn{5}{|c|}{ Direkomendasikan untuk dilakukan fisioterapi pernapasan berdasar atas alasan? } \\
\hline Fisioterapi pernapasan menurunkan risiko VAP. & 84 & 85 & 68 & 86 \\
\hline \multicolumn{5}{|l|}{ Penggunaan tempat tidur kinetik versus tempat tidur standar? } \\
\hline Tempat tidur kinetik menurunkan risiko VAP. & 56 & 64 & 48 & 61 \\
\hline \multicolumn{5}{|c|}{ Diet berlebihan pada pasien dengan ventilator berhubungan dengan? } \\
\hline Meningkatan risiko VAP. & 39 & 44 & 59 & 75 \\
\hline \multicolumn{5}{|c|}{$\begin{array}{l}\text { Manakah rute yang terbaik yang direkomendasikan ketika melakukan intubasi } \\
\text { kepada pasien? }\end{array}$} \\
\hline Intubasi oral direkomendasikan. & 65 & 74 & 71 & 90 \\
\hline \multicolumn{5}{|c|}{$\begin{array}{l}\text { Selama perawatan pasien dengan ventilator, tekanan cuff pipa endotrakeal harus } \\
\text { dipertahankan, karena? }\end{array}$} \\
\hline Berhubungan dengan penurunan risiko VAP. & 73 & 83 & 54 & 68 \\
\hline \multicolumn{5}{|c|}{ Ekstubasi yang tidak direncanakan berhubungan dengan risiko aspirasi, sehingga? } \\
\hline Meningkatan risiko VAP. & 70 & 79 & 68 & 86 \\
\hline \multicolumn{5}{|l|}{ Ekstubasi lebih dini pada pasien berhubungan dengan? } \\
\hline Ekstubasi lebih dini menurunkan risiko VAP. & 80 & 91 & 78 & 99 \\
\hline \multicolumn{5}{|c|}{ Pada saat kapan direkomendasikan untuk mengganti humidifier? } \\
\hline Setiap 2-7 hari (atau kapanpun jika diperlukan). & 42 & 48 & 42 & 53 \\
\hline \multicolumn{5}{|l|}{ Berapa kali dalam sehari perawatan rongga mulut dilakukan? } \\
\hline Kapanpun jika dibutuhkan. & 34 & 39 & 11 & 14 \\
\hline
\end{tabular}

Keterangan: n, jumlah responden; \%, persentase; VAP, ventilator associated pneumonia; ICU, Intensive Care Unit 
Tabel 5 Analisis Pengetahuan Individu berdasar atas Pertanyaan Kuesioner

\begin{tabular}{|c|c|c|c|c|}
\hline \multirow{2}{*}{ Jenis Pertanyaan } & \multicolumn{2}{|c|}{ Perawat } & \multicolumn{2}{|c|}{ Dokter } \\
\hline & $\mathbf{n}$ & $\%$ & $\mathbf{n}$ & $\%$ \\
\hline \multicolumn{5}{|l|}{$\begin{array}{l}\text { Penggunaan profilaksis ulkus peptikum pada pasien dengan ventilator dapat } \\
\text { menyebabkan? }\end{array}$} \\
\hline $\begin{array}{l}\text { Berpotensi meningkatkan kepadatan kolonisasi bakteri aerob pada saluran } \\
\text { cerna. }\end{array}$ & 57 & 64,8 & 45 & 57 \\
\hline \multicolumn{5}{|l|}{$\begin{array}{l}\text { Pendidikan berkesinambungan perawat ICU terkait pencegahan infeksi } \\
\text { nosokomial berhubungan dengan? }\end{array}$} \\
\hline Penurunan angka kejadian VAP. & 61 & 69,3 & 61 & 77,2 \\
\hline \multicolumn{5}{|l|}{$\begin{array}{l}\text { Rasio tingginya jumlah perawat dibanding dengan pasien di ruang rawat intensif } \\
\text { berhubungan dengan? }\end{array}$} \\
\hline Peningkatan risiko VAP. & 46 & 52 & 37 & 47 \\
\hline
\end{tabular}

Keterangan: n, jumlah responden; \%, persentase; VAP, ventilator associated pneumonia; ICU, Intensive Care Unit

HOB 30-45 derajat, penggunaan profilaksis tromboembolik, penggunaan profilaksis ulkus peptikum, pembatasan agen sedatif dan kesiapan esktubasi, serta perawatan oral. Keberhasilan pelaksanaan VAPb oleh dokter dan perawat di ICU bergantung pada standar prosedur operasional, tingkat pengetahuan perawat terhadap VAPb, serta kepatuhan tindakan keperawatan. ${ }^{11}$

Responden penelitian ini, dokter residen dan perawat ruang intensif, telah memenuhi kualifikasi dalam tata laksana pasien dengan ventilator di ruang intensif. Dokter residen yang menjadi responden dimulai dari stase ICU 1 yang telah memiliki kompetensi dalam tata laksana pencegahan VAP menggunakan VAPb. Perawat ruang intensif juga telah memiliki sertifikat pelatihan perawat dasar ruang rawat intensif dan berpendidikan minimal Diploma III.

Implementasi VAPb tidak hanya dilakukan oleh perawat, tetapi berkolaborasi dengan dokter dan juga fisioterapis. Peran perawat dalam VAPb berhubungan langsung terhadap risiko VAP di ruang rawat intensif adalah penggunaan sarung tangan steril, profilaksis aspirasi (elevasi HOB 30-45 derajat dan perawatan rongga mulut), serta menghindari kontaminasi alat bantu jalan napas misalnya sterilisasi dan penyimpanan tabung ventilator. Peran fisioterapis adalah menjaga tekanan cuff ETT adekuat dan menjaga kelembapan alat bantu jalan napas dengan cairan steril. Peran dokter dalam VAPb secara tidak langsung menurunkan risiko VAP, peran dokter dalam rangkaian $\mathrm{VAPb}$ adalah evaluasi dosis sedatif harian dan penilaian kesiapan ekstubasi, penggunaan terapi profilaksis (ulkus peptikum dan DVT), serta indikasi intubasi. ${ }^{10}$

Ventilator associated pneumonia bundle merupakan rangkaian tindakan yang dilakukan bersamaan secara konsisten yang bertujuan mencegah VAP. ${ }^{7}$ Nilai rata-rata pengetahuan $\mathrm{VAPb}$ perawat dan dokter pada penelitian ini berturut-turut 73,63 dan 73,16. Penelitian di Amerika tahun 2010 mendeskripsikan bahwa nilai rata-rata kuesioner VAPb dokter dan perawat 80,2 dan 78,1 masingmasing. ${ }^{14}$ Penelitian di Yaman tahun 2014 mengenai pengetahuan perawat tentang VAPb mendeskripsikan bahwa nilai pengetahuan VAPb berada pada rentang 13,3-80,0 dengan rata-rata $41,32 .{ }^{8}$ Tingkat pengetahuan VAPb akan memengaruhi implementasi VAPb dalam praktiksehari-hari. Pengetahuan tersebutakan menjadi hambatan kepatuhan melaksanakan rangkaian $\mathrm{VAPb}$ sehingga perlu dilakukan upaya meningkatkan pengetahuan responden terhadap VAPb secara menyeluruh. ${ }^{14}$

Pada penelitian ini sebanyak $85 \%$ perawat dan 90\% dokter mengetahui bahwa VAP muncul 48 jam atau lebih setelah pasien terpapar ventilator mekanik. Ventilator assocoiated pneumonia merupakan infeksi 
nosokomial jalan napas dan parenkim paru yang terjadi 48-72 jam setelah pasien terintubasi dan diberikan ventilator mekanik. ${ }^{12}$ Mikroaspirasi mikroorganisme orofaring di sekitar cuff ETT ke bronkus distal, proliferasi, dan invasi bakteri ke parenkim paru merupakan penyebab utama VAP. ${ }^{13}$

Penelitian di Spanyol tahun 2013 mengenai tingkat pengetahuan $\mathrm{VAPb}$ mendeskripsikan bahwa tingkat pengetahuan perawat dan dokter ruang rawat intensif masih rendah, namun kebutuhan protokol VAP dan elevasi HOB 30-45 derajat dapat mencegah VAP yang diketahui oleh lebih dari $90 \%$ perawat dan dokter. Hasil ini berdampak pada implementasi rangkaian pencegahan VAP di ruang rawat intensif itu rendah. ${ }^{15}$

Cuci tangan merupakan aktivitas yang rutin dilakukan oleh perawat dan dokter sebelum dan setelah kontak dengan pasien. Cuci tangan mencegah kontaminasi silang atau kolonisasi mikroorganisme melalui tangan. ${ }^{10,16,17}$ Cuci tangan dilakukan setelah kontak dengan pasien, area sekitar pasien, sekret pasien, serta sebelum dan sesudah prosedur invasif dengan atau tanpa sarung tangan. Sarung tangan harus diganti setelah digunakan. ${ }^{18}$

Penelitian ini mendeskripsikan bahwa $100 \%$ perawat dan dokter mengetahui bahwa protokol cuci tangan harus dilakukan sebelum dan sesudah suctioning oral atau melalui ETT, $84 \%$ perawat dan $67 \%$ dokter mengetahui keharusan menggunakan sarung tangan steril saat suctioning ETT.

Penelitian di Spanyol tahun 2013 mendeskripsikan bahwa hanya 37,5\% dokter dan $64 \%$ perawat mengetahui bahwa higiene tangan sebelum suctioning dan manipulasi sirkuit ventilator. ${ }^{15}$ Penerapan prosedur aseptik yang rendah menjadi salah satu faktor risiko infeksi di ruang rawat intensif. Penerapan prosedur aseptik selama suctioning serta cuci tangan sebelum dan sesudah tindakan berhubungan dengan penurunan risiko kontaminasi mikroorganisme. ${ }^{16}$

Penelitian ini mendeksripsikan bahwa $100 \%$ perawat dan $81 \%$ dokter mengetahui bahwa insersi kateter suction merupakan prosedur steril, $65 \%$ perawat dan $89 \%$ dokter mengetahui suctioning sistem tertutup direkomendasikan, 91\% perawat dan 73\% doktermengetahuikatetersuction harus diganti setelah pertama kali digunakan, dan $82 \%$ perawat dan $65 \%$ dokter mengetahui suction dilakukan apabila diperlukan. Penelitian di Amerika tahun 2010 mendeskripsikan bahwa 92\% perawat dan $90 \%$ dokter mengetahui suctioning sistem tertutup direkomendasikan, $87 \%$ perawat dan $70 \%$ dokter mengetahui kateter suction harus diganti setelah pertama kali digunakan. ${ }^{14}$ Kepatuhan prosedur aseptik pada saat suctioning ETT merupakan salah satu penyebab infeksi di ruang rawat intensif. ${ }^{16}$

Penelitian ini mendeskripsikan bahwa 62\% perawat dan $86 \%$ dokter mengetahui elevasi HOB dilakukan 30-45 derajat, 95\% perawat dan $86,1 \%$ dokter mengetahui fisioterapi pernapasan menurunkan risiko VAP, 64\% perawat dan $61 \%$ dokter mengetahui tempat tidur kinetik menurunkan risiko VAP, 44\% perawat dan $75 \%$ dokter mengetahui diet berlebih meningkatkan risiko VAP, 74\% perawat dan $90 \%$ dokter mengetahui intubasi oral direkomendasikan, $83 \%$ perawat dan $68 \%$ dokter mengetahui tekanan cuff ETT harus dipertahankan, 91\% perawat dan 99\% dokter mengetahui ekstubasi dini menurunkan risiko VAP, 79\% perawat dan $86 \%$ dokter mengetahui ekstubasi tidak terencana meningkatkan risiko VAP, serta $48 \%$ perawat dan $53 \%$ dokter mengetahui penggantian humidifier dilakukan setiap 2-7 hari atau jika diperlukan.

Penelitian di Amerika tahun 2010 mendeskripsikan bahwa $97 \%$ perawat dan 90\% dokter mengetahui elevasi HOB dilakukan 30-45 derajat, $92 \%$ perawat dan $80 \%$ dokter mengetahui tempat tidur kinetik menurunkan risiko VAP, $76 \%$ perawat dan $90 \%$ dokter mengetahui intubasi oral direkomendasikan, serta $26 \%$ perawat dan $50 \%$ dokter mengetahui penggantian humidifier dilakukan 7 hari. ${ }^{14}$ Penelitian di Spanyol tahun 2013 mendeskripsikan bahwa $18,5 \%$ perawat dan $56,3 \%$ dokter mengetahui tekanan cuff ETT harus dipertahankan dan hanya $3,7 \%$ perawat dan 9,4\% dokter mengetahui fisioterapi pernapasan menurunkan risiko VAP. ${ }^{15}$

Aspirasi pada pasien dengan ventilator 
mekanik merupakan penyebab utama mikroorganisme masuk ke dalam parenkim paru dan menyebabkan VAP. Elevasi HOB, penggunaan tempat tidur mekanik, jenis dan pengelolaan humidifier, serta pengelolaan diet menurunkan risiko VAP. ${ }^{16}$ Rute intubasi, sistem suctioning ETT, dan ekstubasi dini menurunkan risiko VAP. Tekanan cuff ETT harus dipertahankan untuk mencegah sekresi yang terakumulasi di atas cuff masuk atau aspirasi karena refluks cairan gastrointestinal dengan dilakukan gangguan fungsi sfingter gastroesofageal akibat pemasangan pipa nasogatrik atau orogastrik. Ekstubasi yang tidak terencana meningkatkan risiko VAP karena tidak dilakukan penilaian kesiapan ekstubasi dan evaluasi obat sedatif. ${ }^{10,16}$

Perawatan rongga mulut mencegah kolonisasi bakteri di rongga mulut dan orofaring. Perawatan rongga mulut juga merupakan bagian dari $\mathrm{VAPb}$ yang dapat menurunkan risiko VAP. ${ }^{19}$ Penelitian ini mendeskripsikan bahwa 38,6\% perawat dan $13,9 \%$ dokter mengetahui perawatan rongga mulut dilakukan jika dibutuhkan. Penelitian di Spanyol tahun 2013 mendeskripsikan bahwa $63,9 \%$ perawat dan $78,1 \%$ dokter mengetahui perawatan rongga mulut mencegah VAP. ${ }^{15}$

Sebanyak $65 \%$ perawat dan $57 \%$ dokter mengetahui penggunaan profilaksis ulkus peptikum meningkatkan risiko VAP secara tidak langsung melalui peningkatan kepadatan koloni bakteri aerob gastrointestinal. Terapi profilaksis yang diberikan pada pasien VAP adalah antibiotik dan obat dekontaminasi oral (chlorhexidine dan povidone-iodine). ${ }^{16}$ Profilaksis ulkus peptikum harus diberikan sesuai dengan indikasi karena peningkatan $\mathrm{pH}$ asam lambung memicu pertumbuhan bakteri sehingga refluks esofageal dan aspirasi melalui ETT. $^{17}$

Sekitar $69 \%$ perawat dan $77 \%$ dokter mengetahui pendidikan berkesinambungan mengenai pencegahan infeksi nosokomial berhubungan dengan penurunan angka kejadian VAP serta $52 \%$ perawat dan $47 \%$ dokter yang mengetahui tingginya rasio perawat dibanding pasien berhubungan dengan peningkatan risiko VAP. Pencegahan dan kontrol VAP di ruang rawat intensif berhubungan dengan edukasi dan pelatihan petugas. Pengetahuan dan pelatihan pencegahan VAP pada perawat dapat meningkatkan kepekaan identifikasi perawat terhadap faktor risiko VAP sehingga kejadiannya dapat dicegah, disamping itu, jumlah petugas ahli infeksi juga memengaruhi angka kejadian VAP. ${ }^{16}$

\section{Simpulan}

Hasil penelitian mendeskripsikan, nilai ratarata kuesioner perawat dan dokter berturutturut 73,63 dan 73,16. Saran perlu dilakukan peningkatan pengetahuan terhadap setiap poin kuesioner yang mempunyai persentase masih rendah. Penelitian ini tidak mengevaluasi implementasi dan kepatuhan mengenai $\mathrm{VAPb}$, oleh karena itu penelitian selanjutnya dapat mendeskripsikan mengenai hubungan tingkat pengetahuan klinisi dengan implementasi $\mathrm{VAPb}$ di ruang rawat intensif.

\section{Daftar Pustaka}

1. Juneja D, Signh O, Javeri Y, Arora V, Dang R, Kaushal A. Prevention and management of ventilator associated pneumonia: a survey on current practices by Intensivists practicing in the Indian subcontinent. Indian J Anesth. 2011;55(2):122-9.

2. Mohamed K. Compliance with VAP bundle implementation and its effectiveness on surgical and medical sub-population in adult ICU. Egypt J Chest Dis Tuberculosis. 2014;63(1):9-14.

3. Ismail R, Zahran E. The Effect of nurses training on ventilator associated pneumonia (VAP) prevention bundle on VAP incidence rate at a critical care unit. J Nurs Educ Practice. 2015;5(12):42-7.

4. Da Silva C, Junior M. Strategies for appropriate antibiotic use in intensive care unit. Einstein. 2015;13(3):448-53.

5. Walkey A, Reardon C, Sulis C, Nace R, Joyce-Brady M. Epidemiology of ventilator associated pneumonia in a long-term acute care hospital. infection control and 
hospital epidemiology. Infect Control Hosp Epidemiol. 2009;30(4):319-25.

6. Pogorzelska M, Stone P, Furuya E, Perencevich E, Larson E, Goldmann D, dkk. Impact of the ventilator bundle on ventilator associated pneumonia in intensive care unit. Int J Qual Health Care. 2011;23(5):538-44.

7. Cal P. Ventilator associated pneumonia prevention bundle. USA: Walden University College of Health Sciences. 2015.

8. Al-Sayaghi K. Prevention of ventilator associated pneumonia: a knowledge survey among intensive care nurse in Yemen. Saudi Med J. 2014;35(3):269-76.

9. O'keefe-McCarthy S, Santiago C, Lau G. Ventilator-associated pneumonia bundled strategies: an evidence-based practice. Worldviews Evid Based Nurs. 2008;5(4):193-204.

10. Lim K, Kuo S, Ko W, Sheng W, Chang Y, Hong M, dkk. Efficacy of ventilator associated pneumonia care bundle for prevention of ventilator associated pneumonia in the surgical intensive care unit of a medical center. J Microbiol Immunol Infect. 2015;48(3):316-21.

11. Walkey A, Reardon C, Sulis C, Nace R, Joyce-Brady M. Epidemiology of ventilator associated pneumonia in a long-term acute care hospital. Infect Control Hosp Epidemiol.. 2009;30(4):319-25.

12. Kalanuria A, Zai W, Mirski M. Ventilator associated pneumonia in the ICU. Crit Care. 2014;18(208):1-8.
13. Subramanian P, Choy K, Gobal S, Mansor $\mathrm{M}, \mathrm{Ng} \mathrm{K}$. Impact of education on ventilator associated pneumonia in the intensive care unit. Singapore Med J. 2013;54(5):281-4.

14. El-Khatib M, Zeineldine S, Ayoub C, Husari A, PK BK. Critical care clinicians' knowledge of evidence-based guidelines for preventing ventilator-associated pneumonia. Am J Crit Care. 2010;19(3):272-6.

15. Perez-Ganda M, Munoz P, Heras C, Sanchez G, Rello J, Bouza E. Prevention of ventilator associated pneumonia:can knowledge and clinical practice be simplyassessed in a large institution? Respir Care. 2013;58(7):1213-9.

16. Ali N. Critical care nurses knowledge and compliance with ventilator-associated pneumonia bundle at Cairo University Hospitals. J Educ Practice. 2013;4(15):6678.

17. Munro N, Ruggeiro M. Ventilator associated pneumonia bundle: reconstruction for best care. AACN Adv Crit Care. 2014;25(2):16375.

18. Said A. Knowledge and practice of intensive care nurses on prevention of ventilator associated pneumonia at Muhimbili National Hospital, Dar Es Salam, Tanzania. Tanzania: Muhimbili University of Health and Allied Sciences; 2012.

19. Alp E, Gundogan K, Guven M, Sungur M. Assessment of risk factors for ventilator associated pneumonia in the medical Intensive Care Unit. Yogun Bakim Dergisi. 2011;2:34-8. 